\title{
LA DONA DE RECORD IMMARCESCIBLE. ECOS ALMERIENSES EN LA OBRA ETIMOLÓGICA DE JOAN COROMINES ${ }^{1}$
}

\author{
JOSÉ ENRIQUE GARGALLO GIL \\ Universitat de Barcelona \\ gargallo@ub.edu
}

\section{RESUMEN}

La «dona de record immarcescible»: así evoca Joan Coromines a su esposa en un poema inserto en el diccionario etimológico catalán (DECat) y fechado el mismo año, 1981, de la muerte de esta. Bárbara de Haro Rodríguez, a quien se refiere siempre mediante alusiones elusivas, tanto en el DECat como en el diccionario castellano e hispánico (DCECH), era originaria de Bédar (Almería), y es sin lugar a dudas la fuente oral que proporciona los datos que Coromines refleja en su obra etimológica, sobre todo en el DCECH. La posibilidad de realizar búsquedas textuales en la edición electrónica de este diccionario (DCECH 2012), tales como «gente de Bédar» o «montañas de Almería», permite la detección de abundantes referencias almerienses, que testimonian una de las múltiples facetas de la poliédrica personalidad del etimólogo.

PALABRAS CLAVE: Almería; Bédar; diccionarios etimológicos; castellano; hispánico; catalán; Joan Coromines.

\section{LA DONA DE RECORD IMMARCESIBLE [THE UNFORGETTABLE WOMAN]. REFERENCES TO ALMERIA IN THE WORK OF JOAN COROMINES}

\section{ABSTRACT}

The «dona de record immarcescible» ['unforgettable woman'] is the way Joan Coromines evokes the memory of his wife in a poem dated 1981, the year of her death, in his etymological dictionary of Catalan (DECat). Bárbara de Haro Rodríguez, to whom he always refers obliquely both in his Catalan etymological dictionary (DECat) and the Castilian and Hispanic one $(\mathrm{DCECH})$, was from Bedar (Almeria), and is certainly the person that provided the data on this area which is reflected in his etymologies, in particular in DCECH. The possibility that the electronic edition of this dictionary (DCECH 2012) offers for conducting phrasal searches like «gente de Bédar» ['people of Bedar'] or «montañas de Almería» ['mountains in Almeria'] leads to numerous local references to Almeria, proof of just one of the multifarious facets of the personality of the etymologist.

KEY WORDS: Almeria; Bedar; etymological dictionaries; Castilian; Hispanic; Catalan; Joan Coromines.

\section{1. «LA DONA D’IMMARCESCIBLE RECORD»}

Oh dona de record immarcescible: / abella, arrop! Que puny més quan no fibla; / encara tornarem per aquelles riberes? / respirarem la flaire d'eternes primaveres? / Oh somni! si ets tan bell, no pots esser impossible (1981) [DECat, s. v. marcir; V, 473b39-444] ${ }^{2}$

\footnotetext{
${ }^{1}$ Agradezco a Joan Ferrer, José Antonio Pascual y Joan Veny la lectura del texto y sus valiosas observaciones.

${ }^{2}$ Cito del DECat i del DCECH por volumen, página(s), columna $(a, b)$ y líneas.
} 
En el artículo correspondiente a marcir de su diccionario etimológico catalán, y concretamente tras la mención del derivado immarcescible, Joan Coromines recuerda de este modo tan especial a su esposa Bárbara de Haro Rodríguez, muerta en 1981. La poesía escrita en memoria de su mujer no se acompaña de explicación alguna, y posiblemente sea una de las inserciones autobiográficas más sentidas, si no la que más, de las que aparecen aquí y allá, en los lugares más insospechados para el lector. ${ }^{3}$

Por más que no tengo constancia del nombre de Bárbara de Haro mencionado explícitamente en la extensa obra corominiana, no son pocas las alusiones elusivas en que no puede ser sino ella la fuente de información de la que bebe el etimólogo catalán. Este otro pasaje del DECat (s. v. lledó) nos servirá de prueba inequívoca:

[...] en la forma que em puntualitzava la dona d'immarcescible record, parlant de la fruiteta: «almecinas... no: latones, como decimos allí» (Bédar, Almería, 1948). [V, 121a5659]

La "mujer de inmarcesible recuerdo", con quien Coromines se casó el 11 de noviembre de 1936 (Pujadas 2008: 520), era originaria de Bédar, una localidad de las montañas de Almería. En el año de referencia, 1948, Coromines se hallaba ejerciendo como profesor de filología románica en la Universidad de Chicago (Pujadas 2008: 525-527), y en algún momento de ese mismo 1948 su mujer volvía a América tras un tiempo de ausencia del país. ${ }^{4}$ Llama la atención, pues, que el autor del pasaje localice en «Bédar, Almería» una información que no pudo recoger in situ, sino, acaso, tras la vuelta de la esposa a Chicago.

En el DECat, el hallazgo de este tipo de alusiones elusivas responde básicamente al azar y a la intuición en la consulta. En cambio, en el DCECH resultan ahora más fácilmente localizables a través de su nueva edición electrónica (DCECH 2012), que ofrece, entre otras posibilidades de búsqueda, la de secuencias textuales a lo largo de todo el texto del diccionario.

\section{LA NUEVA EDICIÓN ELECTRÓNICA DEL DCECH (2012) Y LA “BÚSQUEDA ABIERTA" DE SECUENCIAS TEXTUALES}

«Joan Corominas [...] con la colaboración de José A. Pascual»: es lo que figura acerca de la autoría de la obra original en papel al principio de cada uno de sus seis volúmenes. En la Introducción al diccionario (I, IX-XII), José Antonio Pascual subraya precisamente el papel de colaborador que a él le corresponde, y

\footnotetext{
${ }^{3}$ Tal como advierte Maria Pilar Perea (2006: 115) en la nota 19: «Potser algú s'ha adonat que en aquests versos hi ha un cert reflex dels que Antonio Machado dedicà a Leonor, la seva esposa morta, en Campos de Castilla».

${ }^{4}$ Perea (2006: 114) se refiere a las crisis por las que atravesó el matrimonio, reflejadas de manera tangencial en los epistolarios que reúnen la comunicación por carta entre Coromines y diversos prohombres como Pompeu Fabra o Josep Maria de Casacuberta.
} 
atribuye el de "autor" por excelencia al filólogo barcelonés, que en tantas ocasiones deja en la redacción su impronta y su estilo tan característicos:

Mi labor ha consistido fundamentalmente en dar cuerpo a los materiales escritos por D. Joan Corominas, para hacer posible que luego él, después de revisar escrupulosamente mi trabajo, tomara las decisiones que sólo a él, como autor de la obra, le correspondían, y con las que, por otra parte, siempre he estado de acuerdo. (XII)

En la ficha de Créditos de la edición electrónica los autores aún constan como «Joan Corominas y José Antonio Pascual», mientras que el apellido del primero aparece con la forma «Coromines» tanto en el Manual de ayuda al usuario como en la caja exterior. Y es con esta forma como lo seguiré nombrando en adelante.

En esta utilísima edición, la consulta del DCECH ofrece posibilidades antes impensadas, a través de búsquedas de muy diversos tipos: por lema o sublema, lengua, documentación, étimo, significado, entre otras. La llamada Búsqueda abierta permite la localización de secuencias de caracteres en cualquier punto de la obra. Así, «Bédar» o "Almería», «gente de Bédar» o "gente de Almería», "persona nacida en». Esta última conduce a un par de menciones inequívocas: «Persona nacida en un pueblo de la provincia de Almería», «persona nacida en Bédar», como veremos en el apartado 3.4. El nombre de dicha población, asociado a formulaciones diversas, no deja resquicio a la duda sobre el testimonio de Bárbara de Haro, pero es menos frecuente en el diccionario que el del territorio mayor en que aquella localidad se enmarca, esto es, «Almería». Y es precisamente la elevada cantidad de alusiones a Almería lo que induce a pensar de nuevo en el papel que juega como informante la esposa del etimólogo.

\section{RASTROS TEXTUALES DE «BÉDAR» Y «ALMERÍA» EN EL DCECH (2012)}

Es bien significativo el hecho de que la mayoría de testimonios reflejados en los pasajes que resultan de las distintas búsquedas textuales haya llegado a Coromines a través de fuente oral, o, dicho de otro modo, por vía auditiva («oído en» es una de las búsquedas textuales más fructíferas en este sentido), y no mediante referencias a fuentes escritas, librescas, como es lo habitual para la mayor parte de informaciones del ámbito castellanohablante de España. En algunos casos, es también significativa la constatación sobre el desconocimiento de formas o usos diversos. El conjunto de la muestra aquí ofrecida pone de manifiesto un aspecto de la obra del filólogo catalán en que seguramente muy pocos habrán reparado: los ecos del habla almeriense $\mathrm{y}$, en particular, de la localidad serrana de Bédar. ${ }^{5}$

\footnotetext{
${ }^{5}$ Sobre ello, solo acierto a dar con esta noticia, extraída del blog personal de Juan Antonio Soler El Faro de Bédar. Cosas sobre Bédar: «Se han recogido algunas palabras en Bédar de origen
} 
Bajo cada epígrafe, que presenta entrecomilladas las secuencias de la búsqueda correspondiente, reproduzco, por orden alfabético de lemas de entrada, la transcripción de los pasajes selectos a los que conduce cada búsqueda, seguidos de la localización en la obra original en papel. ${ }^{6}$ Confronto oportunamente la información con la de otras obras (entre ellas, el DECat), y aporto asimismo algunas notas aclaratorias.

\section{1. «Gente de Almería»}

\subsubsection{Alcayata}

Definida por el diccionario como 'escarpia, clavo grande de gancho', se argumenta su procedencia mozárabe, como equivalente del castellano cayada:

Hoy alcayata es muy vivo justamente en esta región [Andalucía], y lo he oído muchas veces a gente de Almería. [I, 134b9-11]

En el Vocabulario andaluz de Alcalá Venceslada (1998: 32): alcayata («Copa de aguardiente»; será acepción secundaria).

\subsubsection{AMAGAR}

Se localiza en Murcia, con remisión a García Soriano (1932: 8); y en Andalucía: amagarse 'agacharse, aplastarse', con remisión a la obra de Alcalá Venceslada [1998: 41]. ${ }^{8}$ La nota 6 precisa sobre Andalucía:

Por lo menos en el Oriente de esta región: se oye mucho a gente de Almería. [I, 29a25-27]

mozárabe, como por ejemplo la forma payuelas (viruelas) o el topónimo Fornos. La recogida de estas palabras usadas en Bédar la debemos, entre otros, a Joan Corominas, famoso filólogo español que estaba casado con Bárbara de Haro, nacida en Bédar y a la que debemos que el filólogo y etimólogo catalán recogiera diversas palabras singulares utilizadas en Bédar, como son latonero, présul, figüelo, sólsa, etc.». [http://blogbedar.blog.com.es/2011/11/10/el-origen-debedar-y-serena-mitos-y-realidad-12147806/; consultado el 30 de enero de 2013]. Si dejamos a un lado la consideración sobre el origen mozárabe de algunas formas, cabe tomar esta noticia como un anticipo de lo que ofrezco en este apartado.

${ }^{6}$ La obra original se presenta a doble columna y con 60 líneas por columna. Véase mi nota 2.

7 Se trata del «Vocabulario del Dialecto Murciano de Justo García Soriano (Madrid, 1932)», según se indica en la ficha del DCECH (I, XLVIII), que añade: «uno de los mejores diccionarios dialectales». En las remisiones a García Soriano (1932) no figuran las páginas de referencia, que completo para facilitar su posible consulta.

8 Véase la ficha bibliográfica recogida por el DCECH (I, XXXVIII): «Antonio Alcalá Venceslada, Vocabulario Andaluz, Andújar, 1933; 2.ํㅡ. ed., M., 1951». Tampoco figuran las páginas de referencia en las remisiones del diccionario a esta obra (cf. la nota anterior). Las completo a partir de la edición que he consultado: Alcalá Venceslada (1998). Ignacio Ahumada escribe en esta sobre la primera edición: «La portada recoge la fecha de 1933, mientras que la cubierta y el colofón reproducen la de 21 de abril de 1934» (Alcalá Venceslada 1998: XX). 


\subsubsection{CANDADO}

A propósito del derivado canadillo, 'belcho, ephedra fragilis, planta gnetácea':

He oído canaíyo a gente de Almería, en cuya provincia es planta muy conocida. [I, 800a1719]

\subsubsection{CENIZO}

Es de interés la referencia a un fraseologismo (parecer un cenizo), de entre los diversos registrados, muestra clara de un conocimiento cercano de la información de origen (véase el apartado 4):

Según noticias orales recogidas de gente de Almería, el cenizo es planta que se emplea para la extracción de sosa, caracterizada porque sus hojas están siempre llenas de polvo: de un objeto polvoriento suele decirse que parece un cenizo. [II, 31b11-15]

\subsubsection{HOPO}

Llama la atención el tratamiento de la consonante inicial en esta formulación en que la referencia a «gente de Almería» no es literal:

opo 'barredor del horno' y 'tirabrasas' en dos [pueblos] de Almería (RFE XXIII, 247, 2534), pero a gente de esta misma provincia he oído la pronunciación jopo, y por cierto en localidades donde no suele conservarse la aspiración [...] (III, 386a42-45)

\subsubsection{MANGANILLA}

Se consignan entre los derivados de esta voz, en Andalucía, desmanganillado y desmangarrillar (con remisión a Alcalá Venceslada [1998: 222]):

recuerdo haber oído enmangarrillado 'renco o lisiado' a gente de Almería [...] (III, 809b2830)

\subsubsection{MEOLLO}

Del cat. molla 'miga de pan' pasó el vocablo con igual sentido al castellano de Murcia [Aut. $]^{9}$ y posteriormente parece haberse extendido a otras hablas castellanas, en el sentido de 'pulpa, molledo' (que, por lo demás, sólo recuerdo haber oído a gente de Almería). [IV, 46b7-13]

9 «Aut.» es la abreviatura empleada en el DCECH para el Diccionario de Autoridades, la primera edición (1726-1739) del diccionario de la Real Academia Española. 


\subsubsection{TAREA}

De la idea de 'imposición de un trabajo' parece venir el matiz especial que Aut. da como aplicación figurada «el afán, cuidado o penalidad que causa un trabajo continuo» [...]. Esta ac. se ha modificado hoy, con carácter más o menos dialectal y familiar, en la de 'idea fija y permanente', 'ocupación que se toma uno en hacer constantemente algo', que he oído a gente de Almería [...] (V, 418b56-457a4)

\subsubsection{ZoTE}

$\mathrm{Su}$ derivado diminutivo forma parte de otro fraseologismo:

el and. zotín, que he oído muchas veces a gente de Almería en frases como no hay ni un zotín, no dejó ni un zotín, es decir, 'nada' [VI, 117a59-b1]

\section{2. «Montañas de Almería» / «Sierras de Almería»}

\subsubsection{CANTUESO}

compárese con el cast. cantigüeso que yo mismo he oído en las sierras de Almería [...] (I, 820a19-20)

\subsubsection{CÍMBARA}

cimbárra es como se pronuncia en las montañas de Almería, según anoté personalmente [...] (II, 77b32-33)

\subsubsection{CINGLETA}

En las montañas de Almería he oído cinglajo, en el sentido de 'harapo, prenda de vestir harapienta', que parece ser catalanismo, aragonesismo o mozarabismo local, derivado del mismo vocablo, con ac. secundaria fácilmente explicable. [II, 87a3-8]

Alcalá Venceslada (1998: 152) localiza cingajo («parte leñosa del racimo de uvas») en Valdepeñas, Jaén.

\subsubsection{CURCUSILLA}

He oído muchas veces curcasilla en las montañas de Almería [...] (II, 297a41-42)

Esta variante de curcusilla ('rabadilla de las aves') la recoge también Alcalá Venceslada (1998: 185) en la provincia de Almería.

\subsubsection{FRIJOL}

[...] murc. frisuelo (Aut.), y figüelo 'habichuela muy pequeña', que he oído en las montañas de Almería, resultante de un cruce de *fisuelo con el nombre judihuelo [...] (II, 958a55-57) 


\subsubsection{GRUMO}

Nota 2: [La ac. 'racimillo de uva'] Es viva actualmente en tierras andaluzas. La he oído en las montañas de Almería. [III, 228a33-35]

\subsubsection{GUIÑAPO}

en las montañas de Almería se dice guiñapero en lugar de 'trapero'. [III, 270b30-31]

\subsubsection{HАTO}

en las Sierras de Almería el hato es el lugar donde los labradores dejan su impedimenta y adonde acuden después a la hora de comer. [III, 326a49-51]

\subsubsection{LASTRA}

Tras la referencia a distintas acepciones de este tipo léxico (lastra, en puntos del castellano peninsular; llastra, en testimonios de la variedad valenciana del catalán), se anota en párrafo aparte:

Pero en las Sierras de Almería lastra de nuevo vuelve a designar un bloque de piedra pendiente y liso en la montaña. [III, 593b54-56]

\subsubsection{LENTISCO}

La variante lantisco, ${ }^{10}$ hoy muy extendida en Andalucía (Acad.; ${ }^{11}$ oída en las montañas de Almería), se explicará por influjo de lanteja [III, 630b8-11].

\subsubsection{MECER}

[...] hoy se extiende el aragonesismo o mozarabismo mejer hasta las montañas de Almería (mejedor o mejelendero 'columpio', oído en Bédar) [IV, 9a35-38]

Compárese con este otro pasaje del artículo COLUMPIAR: «hoy en la prov. de Almería sigue diciéndose mejelendero» [II, 147a53-54]

\subsubsection{MocO}

Nota 2: [mocarro] La variante macarro, registrada por la Acad. y usual, p. ej., en las sierras de Almería, se deberá a influjo de macarrón. [IV, 94a44-47]

Nada señala sobre el significado de esta variante. El DRAE registra macarro con estas acepciones: «1. Panecillo de forma alargada y de una libra de peso. 2. m. Bollo de pan de aceite, largo y estrecho». En Alcalá Venceslada (1998: 371): «Canto de pan con aceite».

\footnotetext{
${ }^{10}$ La edición electrónica registra lamisco, que corregimos por el lantisco de la versión original en papel [III, 630b7].

${ }^{11}$ «Acad.» es la abreviatura que emplea el DCECH para citar las distintas ediciones del DRAE, el diccionario de la «Academia».
} 


\subsubsection{MORUECO}

En este caso, lo relevante es la falta de noticias almerienses que Coromines manifiesta sobre la forma morueco:

Nota 2: Creo que no se emplea en las montañas de Almería. [IV, 159a41-42]

\subsubsection{OSAR}

En ciertas hablas rurales no se ha perdido del todo el empleo popular de osar, p. ej. en las montañas de Almería o en Cespedosa (RFE XV, 142), pero en estos lugares se emplea una forma vulgar usar (nacida por diptongación del hiato en el tipo fraseológico frecuentísimo no osé, no he osado), forma equívoca que contribuiría a la ruina del uso popular de nuestro vocablo. [V, 318a8-16]

\subsubsection{PARAR}

A propósito de paraguas y de su posible equivalencia con quitasol, la nota 20 precisa lo siguiente:

En algunas partes no se distinguen todavía los dos utensilios; en las montañas de Almería se dice sombrilla por 'paraguas', como it. ombrello, ingl. umbrella. [IV, 396b19-22]

\subsubsection{PIOJO}

Una forma vulgar piejo corre entre los charros salmantinos [...] y la he oído en las sierras de Almería ${ }^{12}[\ldots](\mathrm{IV}, 560 \mathrm{~b} 11-15)$

Confróntese con lo escrito al respecto en el DECat (s. v. poll): «En parlars castellans hi ha una variant piejo, a les muntanyes d'Almeria, i en diversos parlars lleonesos [...]» [VI, 654a7-9]

\subsubsection{VALER}

En relación al valor etimológico de valiente, antiguo participio activo de valer:

Nota 1: Con este valor puede llevar complemento directo en la lengua antigua: valient una paja, valient una meaja, Berceo, S. Mill., 202, Mil., 87c. Todavía se dice no gasté valiente una perrilla en las montañas de Almería (ficha antigua que ahora no logro comprobar). [V, 734a15-20]

\subsubsection{YUGO}

Hoy se dice luvio (con aglutinación del artículo) en las montañas de Almería y en Albacete [...] (VI, 21b36-38)

\footnotetext{
${ }^{12}$ Corrijo la errata de la versión electrónica, donde figura Armería.
} 


\subsubsection{ZAFA}

Hoy en las montañas de Almería se considera vulgar, pero sigue siendo bien vivo, con el sentido de 'jofaina, palangana' [...] (VI, 28b18-21)

Se reiteran observaciones similares sobre esta voz y sus sinónimas jofaina y palangana en los artículos correspondientes a estas dos formas:

Palangana es más popular en gran parte de América, desde la Arg. a las Antillas, y asimismo en Almería (donde $p$. es más conocido que $j$., aunque más bien se dice zafa) y muchos puntos del Norte de la Península. [s. v. jofaina; III, 523a34-41]

según datos personales, muy necesitados de comprobación, palangana es usual en Jibraltar [sic] (junto a lavamanos), en Almería (donde es menos popular que zafa), palancana en la prov. de Santander, etc. [s. v. palangana; IV, 349b55-59]

\subsubsection{ZARAGÜELLES}

Hoy sigue diciéndose zaragüel en las montañas de Almería y en otras partes, empleándose mucho en singular. [VI, 86a27-29]

En el DECat (s. v. saragüells) se ofrece una explicación similar, ilustrada con la transcripción de una frase que se fecha en 1938:

cf. la forma castellana antiquada zaragüel, -eles (1490-1575), que és encara la més usada popularment cap a Almeria[,] etc.: «lleva unos pantalones tan paridos que parecen un Aaragzwél» (1938) [VII, 672a42-46]

\section{3. «Gente de Bédar»}

\subsubsection{ESCULLIRSE}

Voz que, con el valor de 'deslizarse', 'caerse', 'escabullirse', la entrada atribuye a Murcia (con remisión a García Soriano 1932: 51) y Almería. En el DRAE (s. v. escullir), con la localización solo de Murcia, y la significación de 'resbalar, caer'.

he oído frecuentemente este vocablo a gente de Bédar (zona montañosa de Almería), donde escullirse es además 'escurrirse de las manos (como la seda, p. ej.)' [...] (II, 719b60720a3)

\subsubsection{JARDÍN}

A pesar de no responder textualmente a la secuencia «gente de Bédar», incluyo aquí este pasaje, de formulación afín:

en Bédar (Almería) jardín es voz desusada entre la gente del país y se llama huerto al jardincito contiguo a la casa destinado al recreo y al cultivo de flores. [III, 496a27-30]

\subsubsection{RANA}

Ranueco almer. 'renacuajo' (oído a gente de Bédar) [...] (IV, 767a2-3) 
El mapa 428 del ALEA $^{13}$ registra el tipo "ranueco" en tres puntos almerienses: Cantoria (Al 400), Vera (Al 402) y Lubrín (Al 403).

\subsubsection{SOPONCIO}

[...] lo pone Juan Valera en boca de su popular criada andaluza Antoñona, quien encontrando a su ama, la enamorada Pepita Jiménez, echada al suelo en un desconsuelo de gemidos y sollozos, exclama: «¿qué soponcio es éste?» [...]; en efecto, en el sentido de 'disgusto grave' lo he oído a gente de Bédar, Almería (¡tuve un soponcio!). [V, 308a35-43]

\subsubsection{SOSA}

Para reforzar el argumento de un cruce entre el árabe vulgar sáỗda y una antigua denominación romance SALSELLA 'saladita', que daría como resultado cierta forma «mozárabe», se trae a cuento un testimonio de Bédar:

Nota 1: Un recuerdo de este cruce perdura en la forma solsa, que he oído a gente de Bédar (Almería). [V, 316a50-52]

\section{4. «Persona nacida en $[\ldots] » y$ afines}

\subsubsection{CURRO}

Sobre el nombre propio de persona Curro, hipocorístico de Francisco y abreviación de Pacurro, el diccionario señala:

Nota 1: Persona nacida en un pueblo de la provincia de Almería, me dice que allí Curra se ha convertido en el apodo hereditario de una familia, lo cual no indica una gran frecuencia en la localidad, pero es que este nombre abunda más en la zona de Sevilla y Andalucía occidental, que es la que suele mirarse como más típica. [II, 300a57-b4]

El Vocabulario andaluz de Alcalá Venceslada (1998: 186) incluye este antropónimo.

\subsubsection{ENRUNA}

Voz que se registra como aragonesa, albaceteña y murciana, con las significaciones de 'escombros, cascotes', 'cieno, tierra de aluvión'. En cambio, se omite la referencia a Albacete en la nota 5, y se informa sobre el desconocimiento de dicha forma en Almería:

El caso es que nuestra familia lingüística en español es exclusivamente aragonesa y murciana; enruna es ya desconocido en Almería, según me informa persona nacida en Bédar. [II, 639b57-60]

\footnotetext{
${ }^{13}$ Se trata de uno de los atlas lingüísticos peninsulares que, como tantas otras obras de las últimas décadas, Coromines habría de renunciar a despojar durante la elaboración del DCECH. Sobre ello véase el apartado 4 .
} 
Hallamos una noticia paralela en el DECat: «ja no [se usa], però, cap a Almeria, desconegut a Bédar» [s. v. runa; VII, 534b45-46].

Por su parte, el DRAE localiza enruna («Cascote, escombros o desperdicios que sirven para solar») solo en Aragón.

Añado a continuación un par de testimonios con formulaciones muy afines a la del epígrafe entrecomillado:

\subsubsection{ESQUILAR}

El catalán cap d'esquila, locución pastoril o pecuaria referida a la cabeza de ganado que siempre sufre el esquileo, conduce en este pasaje a un nuevo fraseologismo, en que se incluye el sintagma burro de esquila:

Nota 4: en el mismo sentido oí la frase tomar por burro de esquila a persona de Bédar (Almería). [II, 758b46-50]

\subsubsection{PECHINA}

Se trata de otra noticia sobre el desconocimiento de una forma concreta (ahora, pechina) en diversos lugares de la península:

personas nacidas en Santander, Luarca, Málaga, Almería, Madrid, León, Zaragoza y Buenos Aires ignoran todas qué es una pechina [IV, 453a45-47]

\subsection{Otras menciones de «Bédar»}

Los siguientes pasajes incluyen «Bédar» con formulaciones diversas:

\subsubsection{ALMARJO}

Nota 2: Hay pueblo llamado El Marchal, en el fondo de un barranco, junto a Bédar, prov. Almería. [I, 187a2-4]

Es uno de los diversos topónimos de la zona mencionados en esta muestra (véase el apartado 4).

\subsubsection{AMAPOLA}

Nota 1: Hoy se dice así [amapol] en Bédar (Almería). [I, 232a-57]

El ALEA (mapa 295. Amapola) registra el tipo "amapol" en distintos puntos de la provincia de Almería. Recogen asimismo dicha variante el Vocabulario andaluz de Alcalá Venceslada (1998: 42) y, en Jaén, Becerra / Vargas (1986: 24).

\subsubsection{BRUCES, DE}

La locución antigua de buzos o de buces contiene la forma primitiva de la que deriva abuzado: 
Nota 7: Abuzado significa 'echado hacia la frente' en Bédar, Almería (llevar el pañuelo abuzado). [I, 678a50-52]

En Alcalá Venceslada (1998: 14): abuzar («Echar para abajo una cosa»).

\subsubsection{CANGILÓN}

Ofrece otro fraseologismo, comparable en su motivación al del castellano a espuertas ('a montones, en abundancia'):

en Bédar (Almería) se habla hoy de hacer comida a cagilones (en gran cantidad) [...] (I, 805b34-35)

\subsubsection{CATE}

Entre las voces emparentadas con el lema inicial (CATE, 'bofetada, golpe, paliza'), se recogen catite y catita, que apuntan a la idea común de 'pequeño':

En Bédar (Almería) se emplea dedo catite 'dedo meñique' y gallina catita para una raza inglesa de pequeña talla; lo primero podría explicarse por catite 'palito', pero lo segundo es más difícil [...] (I, 923a29-33)

El ALEA registra para 'dedo meñique' (mapa 1273) tite en algunos puntos de la Andalucía oriental. A partir de este atlas, Julià (2012: 250) se hace eco en Andalucía de esta forma y de una designación trisílaba garite; ambas, posiblemente vinculadas a catite.

\subsubsection{CENTENO}

Nota 3: El nombre de lugar Centinares (Bédar, prov. Almería) quizá venga de otra forma mozárabe *entino. [II, 33b5-7]

\subsubsection{COMER}

De los múltiples derivados de comer, reconcomio conduce a otros afines como regomeyo, que el DRAE localiza en Murcia y Almería, y regomello, que el diccionario académico atribuye solo a Murcia, con remisión a la variante anterior.

Nota 3: [regomello] Acad. ya 1925, como murc. «disgusto que no se revela al exterior»; [...] «empacho, cortedad» (usado en Murcia, Orihuela y Villena) [con remisión a García Soriano 1932: 109-110]; A. Venceslada [1998: 535] dice que se emplea en toda Andalucía, y agrega regomellar 'refunfuñar' y 'tener regomello'. En efecto lo he oído en Bédar (Almería) en un sentido como 'recelo, resentimiento'. [II, 159a1-9]

\subsubsection{CORTO}

[curto] con la ac. latina 'rabón' sigue empleándose esta variante en Aragón [Acad. ya 1843] y la he oído en Bédar (Almería). [II, 216a51-55] 
El DECat (s. v. curt) anota escuetamente: «perro curto, caballo curto 'escuat' serres d'Almeria (1948)» [II, 1112b59-60]; de nuevo con el año 1948 como referencia en esta obra (cf. los apartados 1 y 4 ).

El DRAE remite curto a corto y a rabón, en ambos casos con localización en Teruel. Salvador (1953: 153) registra perro curto entre los aragonesismos del andaluz oriental. Alcalá Venceslada (1998: 186) consigna, además de la acepción genérica de 'corto' y la específica de 'rabón', un uso familiar: «Dícese del individuo de pene corto».

\subsubsection{ESQUILMAR}

[Del antiguo esquimar:] Esquimo significa en Bédar (Almería) la acción de coger todos los chumbos de un ribazo, alquilado a este efecto por su dueño. [II, 759b12-15]

\subsubsection{FALDA}

Nota 4: [Como evolución del tipo derivativo falduda:] Jardúa 'mujerona', 'mujer de mala reputación', en Bédar (Almería), recuérdese el haldear característico de la Celestina. [II, 839a38-40]

Es de notar que abundan en la muestra las referencias al concepto de 'mujer de mala reputación': véanse, más abajo, gamberra (3.6.32), liebre (3.6.46), escardillo (3.6.48) y purrupiala (3.6.56).

\subsubsection{FANTASÍA}

[Del lat. vg. PANTASIARE 'soñar', 'tener pesadillas'] and. pantoseo 'acción de jadear' (oído en Bédar, Almería). [II, 852a12-13]

Ofrece un testimonio paralelo el DECat (s. v. fantasia): «andal. pantoseo “acción y efecto de jadear" (sentit a les muntanyes d'Almeria)» [III, 879b3-4].

\subsubsection{GARABATO}

De la misma familia léxica que garabato, y de acuerdo con la idea de "lo engarabatado", resultan un par de derivados, sinónimos entre sí:

Bédar (Almería) garabuyo o garabazo 'pan de forma romboidal alargada'. [III, 81a17-18]

\subsubsection{GARBILLO}

lo he oído también en Bédar (Almería), donde se distingue entre garbillo 'criba para grano' y zaranda 'íd. para el arroz'. [III, 88b38-41]

Una observación muy semejante figura en el DECat (s. v. garbell) con la indicación de 1944, en que Coromines residía en la Argentina, un par de años antes de su traslado a la Universidad de Chicago (Pujadas 2008: 523-525):

Jo ho he oït al NNE. D'Almeria (on distingeixen garbillo, l'usat per al blat, de zaranda, el de l'arròs, 1944) [...] (IV, 358b39-41) 


\subsubsection{HARAPO}

Harapa (pron. con $h$ aspirada) 'manta de tiras de trapos' en Jaén (RFE XXIII, 248) 'lienzos que se ponen debajo de los olivos al recoger la aceituna' en Granada (ibid., 251), íd. en Bédar (Almería) [III, 318b25-29]

\subsubsection{LATÓN II}

Según García Soriano [1932: 75] se dice lirón, -ero, en el Centro, Sur y Sudeste de Murcia, alatón, -ero, en el Noroeste de esta región; latón he oído también en Bédar (Almería) [III, 605a23-26]

Latón figura como aragonés en el DRAE, que remite al nombre del árbol (almez) y al del fruto (almeza). El DECat (s. v. lledó) recoge el testimonio, transcrito en el apartado 1, de la «dona d'immarcescible record»: «"almecinas... no: latones, como decimos allí" (Bédar, Almería, 1948)» [V, 121a56-59].

\subsubsection{LIRÓN I}

en Bédar (Almería) llaman lero a un bicho que vive oculto en un agujero que él mismo se abre en el suelo: los niños, que lo persiguen cantándole las palabras lero, lero, sal del agujero, tienen miedo de los ojos con que se los mira y temen su mordedura (?); otros le llaman laurel, quizá deformación voluntaria, por una especie de tabú infantil causado por este temor. [III, 665a27-34]

\subsubsection{MATRERO}

Quizá sea voz más viva en América que en España, donde, sin embargo, la encontramos en la toponimia (cortijada de Los Matreros, en Bédar, Almería) [...] (III, 885b43-46)

\subsubsection{PAJA}

Nota 1: Variante mozárabe parece ser payuelas 'viruelas locas' [Acad. 1884], oído en Bédar (Almería); la grafía correcta sería palluelas. [IV, 342b32-33]

El DRAE remite payuelas a viruelas locas. Recoge asimismo payuelas («Viruelas locas») el Vocabulario andaluz de Alcalá Venceslada (1998: 461).

\subsubsection{QUEBRAR}

Nota 8: En Bédar (Almería) se llama quiebraollas cierta planta silvestre; pero, en forma análoga, también es corriente oír quebraollas. [IV, 708a50-53]

\subsubsection{SILO}

de Bédar (Almería) he anotado ensilarse 'perder el tiempo haciendo algo muy despacio', 'quedarse mucho rato en un lugar' (como el trigo o el prisionero en el silo; o más bien por el mareo que sobrecoge al que penetra en un silo, lleno de gases mefíticos [...]) [V, 249a10-16]

En Alcalá Venceslada (1998: 248), ensilarse: «Ensimismarse. Echar mucho tiempo en una faena». 


\subsubsection{SISCA o JISCA 'carrizo'}

[García Soriano 1932: 120] da sisca en Murcia [...]; de Bédar, parte alta de esta provincia, tengo anotado cisca (allí no confunden la $s$ con la $c$, mas puede tratarse de una forma arabizada). [V, 263b26-31]

Hallamos una anotación que se diría paralela de la anterior, pero en forma de alusión elusiva a "su inolvidable", en el DECat (s. v. sisca):

de Bédar, NE. D'aquesta ciutat, la meva inoblidable coneixia bé cisca $-\mathrm{i}$ allí ningú no confon la $s$ amb la $c-$, però es pot tractar d'una forma arabitzada. [VII, 949949a58-60]

\subsubsection{SOCARRAR}

De entre las numerosas variantes dialectales que presenta este tipo léxico en la península, una se atribuye a Bédar:

Chascurrar (presente chascurro) anotado de Bédar (Almería) [V, 284a22-232]

\subsubsection{VARIO}

De la familia derivativa de viruela (del lat. vg. VARIŎLA íd.) forma parte el adjetivo virolento, que presenta una variante metatética en el topónimo referido:

hay aldea llamada los Vilorentos, con metátesis, cerca de Bédar, Almería [V, 748a6-7]

\subsection{Otros testimonios almerienses}

Si en la versión electrónica del DCECH (2012) se lleva a cabo la búsqueda abierta de la secuencia "Almería» en todo el texto, como resultado se obtienen 222 registros. Muchos de los pasajes en que se inscribe el nombre de esta provincia reflejan claramente, o cuando menos dejan entrever, un conocimiento vivencial de las palabras y la realidad descrita. No pocos contienen la secuencia del participio «oído», que testimonia la proximidad de una información oral no necesariamente registrada in situ, sino de labios de la esposa del etimólogo, que recurre sistemáticamente a la metonimia: "lugar de procedencia por persona que de allí procede". Veamos una nutrida selección de citas del DCECH, algunas con el contrapunto del DECat:

\subsubsection{ACEROLA}

Quizá proceda de azarolla 'acerola' el adjetivo cerollo o zorollo [...] zorollo en Almería se aplica a un manjar medio crudo. [I, 35a44-50]

En el artículo correspondiente a ZARAZAS (nota 3) se recoge este mismo valor: «zorollo, que en el sentido 'a medio cocer' he oído en Almería y se empleará en otros puntos de España» [VI, 94b5-7]. 
El DRAE atribuye al adjetivo zorollo, lla el significado más genérico de 'blando, tierno'. En Alcalá Venceslada (1998: 663) este mismo adjetivo presenta entradas diversas y distintas acepciones.

\subsection{2. АСНUСHAR}

La entrada atribuye a esta voz de creación expresiva las acepciones 'empujar bruscamente', 'aplastar' y 'azuzar'. La primera de ellas -se lee más abajo«la he oído en Almería». Alcalá Venceslada (1998: 19) registra el uso andaluz de tal acepción («Empujar una cosa»).

\subsection{3. АMBUESTA}

Almería almostrada (pron. armohtrá) [I, 239a60-b1]

Cf. con el DECat (s. v. embosta): «el consonantisme primitiu en -st- no reprèn fins a Almeria almostrada (pron. armohtrá)» [III, 281b33-34]. Alcalá Venceslada (1998: 39) localiza almostrada en Almería, y proporciona el siguiente ejemplo: «Le dió [sic] una almostrá de garbanzos tostaos».

\subsubsection{AZUFAIFA}

el cast. jinja [...] y jínjol [...] Aut. [= Diccionario de Autoridades] cita sólo el segundo, pero como desusado: hoy se emplea en Almería [...] [I, 438b46-48]

Más abajo se cita el derivado jinjolero con la indicación entre paréntesis de «Almería». Ambas formas, jínjol y jinjolero, son remitidas por el DRAE a azufaifa (el fruto) y azufaifo (el árbol). El ALEA (mapa 314. Azufaifo) registra los tipos “jinjolero" y "jínjole(s)" en distintos puntos de la provincia de Almería. Véase, además, este otro pasaje del DECat (s. v. gínjol), en que el año de referencia (1936) corresponde al de la boda con Bárbara de Haro:

Encara que en castellà comú és azufaifa, $[\ldots]$ el nom català ha penetrat en certa mesura en zones orientals castellanes, des de València [...], Sogorb [...], murc. jínjol [con remisión a García Soriano 1932: 71] i he sentit hínholes jo mateix a gent de les muntanyes d'Almeria (1936) [IV, 500b46-53]

\subsubsection{BARRUNTAR}

Aberruntar y barruntar. La primera de estas formas la he oído en Almería: la forma de arder el fuego aberrunta viento 'señala, anuncia' [...] (I, 531a19-22)

\subsubsection{BOINA}

A propósito de su acentuación, se lee en la nota 2: «oí boína en la provincia de Almería» (I, 614a9-14). 


\subsection{7. САBO}

En relación a la forma murciana camota ('cabezota', 'tocón'), adaptada a partir del catalán cabota ('cabezota', 'cabeza de clavo'), que a su vez deriva de cap 'cabeza', la nota 2 precisa:

En Almería dicen camocha, con igual valor afectivo, por 'cabeza': estará por *cabocha (fr. caboche), con influjo de mocha y escamocho. De ahí la -m- pasaría al sinónimo camota. [I, 715a3-7]

Alcalá Venceslada (1998: 19) atribuye a Jaén camorcia ('cabeza') con la notación de su uso "familiar" y "festivo".

\subsubsection{CALAMÓN}

Tampoco es claro semánticamente el and. calamonazo 'cabezada contra la pared' (muy usado en Almería) [...] (I, 754b60-755a2)

De la misma familia léxica serán los testimonios de Alcalá Venceslada (1998: 114): calamón (Granada), calamollazo (Málaga); ambos, definidos como «[g]olpe dado a otro en la cabeza»; calamonada («Cabezazo»), calamonazo («Golpe con la cabeza») y calamorrate («Calamollazo»).

\subsubsection{CÁMARA}

En castellano predominan modernamente las acs. eruditas, pero la de 'piso alto donde se guardan las viandas y el grano' [...] es popular todavía en algunas partes, p. ej. en Almería. [I, 779b34]

El DRAE registra cámara con dicha acepción: «5. En casas de labranza, local alto destinado a recoger y guardar los granos».

\subsubsection{0. $C A N$}

*encañarrarse, *cañarra, derivados del prehistórico *caña 'perra' [...]; del mismo origen quizá and. carrañaca ‘birria, cosa despreciable' (Almería). [I, 794b26-29]

En Alcalá Venceslada (1998: 136), carrañaca: «Cosa vieja y descompuesta. Se dice así porque suele crujir».

\subsubsection{CAPORAL}

Se trata de un italianismo del lenguaje militar. Hoy sigue empleándose [...] en la prov. de Almería, en comparaciones (parece un c.). [I, 836a55-60]

La comparación expresada por "parecer un caporal" constituye uno de tantos ejemplos extraídos del habla viva (véase el apartado 4). 


\subsubsection{CARA}

careto 'animal que tiene la cara blanca y el resto de la cabeza oscuro' [Acad. ya 1817]; [...] en Almería 'fruto fallado, malo (particularmente el chumbo)', 'persona mala o inútil' [I, 841a43-49]

\subsubsection{CARAMELO}

Este lusismo, que presenta la terminación (-elo) heredada en portugués a partir del sufijo latino -ELLU (CARAMELLU), da pie a una variante caramel, cuyo tratamiento en el Tesoro de la lengua castellana o española de Covarrubias (1611) conduce al testimonio almeriense del valor de 'sardina pequeña':

En cuanto a la forma caramel registrada por Covarr., se explica fácilmente como adaptación de la terminación extranjera y rara -elo a la más frecuente -el. El mismo lexicógrafo considera caramel en el sentido de 'especie de sardina pequeña que se coge en la región de Cartagena' (oído hoy en Almería) como aplicación figurada de caramel 'caramelo' (quizá por la forma alargada) [I, 851b52-59]

\subsubsection{CENACHO}

En castellano designa una especie de capacho o espuerta para llevar viandas de muchas clases; concretamente puede servir para llevar pescado a vender (así en Andalucía, a juzgar por el derivado cenachero, 'el que lleva un cenacho de esta clase' [...], para ir a buscar setas (oído así en Almería), y otros usos semejantes [...] (II, 24a18-25)

La especificidad de Almería consiste en el uso del cenacho «para ir a buscar setas». La definición del DRAE (s. v. cenacho) apunta a su utilidad para llevar en él viandas diversas: «Espuerta de esparto o palma, con una o dos asas, que sirve para llevar carne, pescado, hortalizas, frutas o cosas semejantes».

\subsubsection{CERRIÓN}

Por influjo de chorro, cerrión se ha convertido en chorreón en el habla de Almería, donde llaman así los cilindros de hielo que cuelgan de una ventana, etc., y también las manchas largas causadas por un chorro de líquido sucio. [II, 53a31-35]

Ambas acepciones de chorreón remiten claramente al conocimiento directo del hábitat (la de 'carámbano') y de la vida cotidiana (la de 'mancha alargada').

\subsubsection{CIMBRA}

Cimbre m. 'galería subterránea' [Acad. 1899], por la forma abovedada, de donde secundariamente and. cimbra 'galería subterránea de agua' [información que remite a Alcalá Venceslada 1980: 151], Almería íd. 'acequia grande al descubierto' (oído allí). [II, 79a23-27]

\subsubsection{CHAPUZAR}

[capuzar] Éste figura en la Acad. ya en 1817 (no 1783), sin localización, mas parece ser voz propia de las hablas castellanas del Este, pues capuzón 'chapuzón' es murciano según la 
Acad. y yo lo he oído en Almería [...] y no parece que capuzar sea ajeno a otras regiones de España, pues lo he oído en Almería [...] (II, 333b19-33)

El DRAE remite capuzar a chapuzar, y capuzón (como voz aragonesa) a chapuzón. El DECat (s. v. cap) se hace eco de ambas voces en las montañas de Almería: «almenys s'usa capuzar a les muntanyes d'Almeria, el verb i un substantiu capuzón 'capbussó'» [II, 515a49-51]; y remite a la nota 20, de contenido vivencial:

«Capuzón de la Virgen pura, / que no me dé frío ni calentura», formuleta que recitaven els noiets a Bédar, c. 1920, abans de capbussar-se en una bassa. [II, 523a49-52] ${ }^{14}$

\subsubsection{CHÍCHARO}

Nota 2: En Almería, si estoy bien informado, el chícharo es un grano que se da de comer a los cerdos. [II, 355a19-21]

En el DRAE, chícharo: «Guisante, garbanzo, judía».

\subsubsection{CHILINDRINA}

Almería chilindrino ‘muchacho (como término afectivo e irónico)’ [II, 358b30-31]

Véase un testimonio afín en el califa del punto 3.6.31.

\subsubsection{0. СIPOTE}

se emplea como término insultante en el sentido de 'bobo, tonto' en Almería (oído allí) [...] (II, 88a29-30]

Coincide con la segunda acepción de cipote en el DRAE: «Hombre torpe, zonzo, bobo». En Alcalá Venceslada (1998: 152): «Zonzo, torpe de modales o de expresión». Es registrado asimismo en Jaén como término afectivo insultante por Becerra / Vargas (1986: 148).

\subsubsection{COCHINO}

En Almería he oído muchas veces cuchimán 'habitación estrecha y desaseada, chiribitil', que resultará del and. cachimán 'desván, puesto de vender', al parecer de origen gitano [...], alterado por influjo de cuchitril [...] (II, 115a32-37)

\subsubsection{CONOCER}

Contiene un par de transcripciones de ejemplos extraídos del habla viva: «Conocio and., fam., 'íd., magín' (no tiene c., perdió el c., oído en Almería)» [II, 176b21-22].

\footnotetext{
${ }^{14}$ He oído una fórmula semejante en el Rincón de Ademuz (Valencia): «Capucete de Cristo, cojo la ropa y me visto».
} 


\subsubsection{COSCORRÓN}

Cuscurronero o -rrunero 'que se deja masticar fácilmente y cruje al masticarlo, lo contrario de correoso', palabra no recogida por los diccionarios, usual en Almería y otras partes. [II, 221a17-20]

En Alcalá Venceslada (1998: 186): cuscurreante («Que cuscurrea»); cuscurrear («Triturar con las muelas un cuscurro u otro alimento duro»).

\subsubsection{COSER}

Corcusir 'tapar a fuerza de puntadas mal hechas los agujeros de la ropa' [...] cat. (val., or.) culcosir [...]; esta forma con $u$ [llamada a la nota 3] y $l$ es la originaria, pues se trata de un compuesto con culo, en el sentido de hacer, como suele decirse, un «culo de gallina», o zurcido somero formando bolsa [II, 221b6-15]

Nota 3: Oído así muchas veces en la provincia de Almería. [II, 221b24-25]

\subsubsection{COSTRA}

Custrirse 'cubrirse de costra, endurecerse' en Murcia [con remisión a García Soriano 1932: 36], 'endurecerse, agrietarse (el cutis por el frío)' en Almería: tiene los labios custridos, pan custrido [...] (II, 223b14-17)

Confróntese su significado con el registro del DRAE, que localiza custrirse («Cubrirse de costra, endurecerse») en Andalucía y Murcia. En Alcalá Venceslada (1998: 186): custrido, da («Costroso, cortezudo») y custrío, tría («Herpes o eczemas en la piel»; con localización en Los Villares, Jaén).

\subsubsection{CUNDIR}

Pero lo más frecuente es que percu(n)dir tuviera sentido desfavorable, y así es como se emplea hoy, aplicándolo especialmente a la suciedad, en lugares muy diversos: en Almería, donde he oído hablar muchas veces de ropa empercudida que no queda limpia al lavarla [...] (II, 292b1-6)

En el DRAE, empercudir: «Dicho de la suciedad: Penetrar en algo, especialmente en la ropa manchada o mal lavada».

\subsubsection{ENGREÍRSE}

hoy creído es de uso popular en muchas partes y con el mismo sentido: lo he oído repetidamente en Almería para 'mimado' y 'presuntuoso' [...] (II, 625b39-42)

Cf. el DRAE (s. v. creído, da): «adj. coloq. Dicho de una persona: Vanidosa, orgullosa o muy pagada de sí misma».

\subsubsection{ENTONCES}

Nota 2: En tierras de Almería, en el habla rápida, se oye también ¿pwé ntóh ké? (= ¿pues entonces qué?). [II, 644a15-17] 
Se trata de una noticia de fuente oral relativa a la fonética, como la referida a la pronunciación de cebrero por febrero, por equivalencia acústica, que cito más abajo (3.6.36).

\subsubsection{FARFOLLA}

Perfolla 'envoltura de la mazorca del maíz' es murciano (así Acad., ya 1884 [con remisión a García Soriano 1932: 98] y andaluz [con remisón a Alcalá Venceslada 1980: 473], pero creo que en esta región es propio de la parte oriental [...], yo lo he oído en Almería [...] (II, 865b43-48)

En el DRAE, perfolla se localiza en Murcia. Salvador (1953: 151) registra parfolla en Granada, entre otras variantes de este aragonesismo en el andaluz oriental. El ALEA (mapa 105. Farfolla) testimonia el tipo "perfoya" en la mitad oriental de la provincia de Almería.

\subsubsection{FAYANCA}

Afayancarse 'tropezar en algún objeto saliente en el suelo', 'apuntalarse con los pies en alguna parte' (oído en Almería). [II, 876b13-15]

\subsubsection{GALAVARDO}

califa, que en Almería significa 'muchacho travieso', 'persona poco recomendable'. [III, 30b53-54]

\subsubsection{GAMBERRO}

gamberra, Acad. 1899, como voz andaluza en el sentido de 'mujer pública'.

En ediciones posteriores se ha agregado, sin nota de localismo, la ac. transcrita arriba, que me es bien conocida en el habla popular de Almería en calidad de dicterio. [III, 58a45-50]

En efecto, en la edición del DRAE que aquí cito (s. v. gamberro, rra), la acepción 3 (en femenino), localizada en Andalucía, remite a prostituta.

\subsubsection{GÁNDARA}

en Andalucía este vocablo [gandul] designa un árbol de ramaje caído (anotado en Almería) y es por lo tanto lo mismo que el común gandul 'perezoso', de origen arábigo. [III, 72b8-11]

\subsubsection{GIBA}

Hoy en muchas partes (p. ej. Almería) es más popular que JOROBA [...] (III, 147bb18-20)

\subsubsection{GRILLO}

Es de notar que hoy en muchos puntos del Sur de España se emplea grillo como única denominación del saltamontes o langosta; así, p. ej., en la provincia de Almería. [III, 214b32-36]

Sobre esta extensión del sentido de grillo, véase el DECat (s. v. grill): 
A l'Alt Aragó i altres zones castellanes sembla haver-hi trasllat semblant a insectes anàlegs: grillo és una espècie de 'llagost' a Linás de Broto (igual a les muntanyes d'Almeria) [...] (IV, 660a14-17)

Véase asimismo, a propósito de la interferencia de la designación de 'grillo' con la de otros insectos en el dominio catalán, así como en el ámbito aragonés y en el andaluz, el estudio de Joan Veny (1988).

\subsubsection{HEBILLA}

Nota 7: en la provincia de Almería se oye muchísimo cebrero por febrero. [III, 337b17-19]

\subsubsection{HORADAR}

Horambre 'agujero en el molino de aceite' [Acad. ya 1817], jolambre 'agujero del yugo donde se ata la mediana' (en un pueblo de Almería) [...] (III, 390a50-53)

En Alcalá Venceslada (1998: 345), jolambre: «En los molinos de aceite, cada uno de los agujeros que tienen las guiaderas por los que se mete el ventril».

\subsubsection{HURAÑO}

hurón, animal arisco por excelencia, cuyo nombre efectivamente ha tomado el sentido de 'arisco, huraño', aplicado a personas, en castellano moderno [fin S. XVIII, Moratín], hoy vivo en autores andaluces [...] y oído por mí en Almería y en otras partes. [III, 430b31-37]

El DRAE (s. v. hurón) registra para esta voz la misma acepción ('persona huraña') como "coloquial".

\subsubsection{INDULGENTE}

hoy endurtao se emplea vulgarmente en Almería en el sentido de 'seguro, al abrigo de todo peligro' [...] (III, 448b50-52)

\subsubsection{IRONÍA}

Nota 1: Murc. inronia 'rencor, odio, mala intención' [remisión a García Soriano 1932: 69] tener mala inronia 'saña, mala sangre', que he oído muchas veces en la prov. de Almería [...] (III, 464b32-36)

En Alcalá Venceslada (1998: 333), inronia: «Animosidad, aversión, odio».

\subsubsection{JIRA}

en muchos puntos de España (p. ej. en la prov. de Almería), sigue bien popular en el sentido de 'comida campestre' (ingl. picnic), pero desde luego sin el sentido erróneo de 'excursión' ni ‘viaje'. [III, 520a54-56]

\subsubsection{JUREL}

es la forma más extendida en castellano [...], la he oído en Almería [III, 540b41-43] 


\subsubsection{LACHA}

he oído poca lacha 'falta de vergüenza' en Almería (...) [III, 552b27-28]

\subsubsection{LAMPAR}

Lampio como sinónimo de limpio se emplea en Almería como voz jocosa o agitanada, y resultará de un cruce de este último con lampante. [III, 567b35-38]

\subsubsection{LAÑADO}

Hoy me son bien conocidos lañado y lañar en el lenguaje vivo de Almería, con aplicación a cántaros y otras vasijas reparadas con alambres, o en forma semejante, a fin de que no acaben de romperse cuando están hendidas o simplemente sentidas de un golpe [...] (III, 576b46-51)

\subsubsection{LIEBRE}

alebrastarse (Acad.) y alebrestarse; en Cuba [...] y Colombia [...] 'excitarse sexualmente', quizá relacionable con el empleo que se hace en la prov. de Almería de mala liebre, y algunas veces liebre a secas, en el sentido de 'mujer deshonesta' [III, 645b8-15]

\subsubsection{LAR}

Y el hecho es que los llares o cadenas del hogar son un enser propio del Norte de España, y aunque se emplee en partes del Centro y aun algún punto del Sur, de una manera general es ajeno a la casa andaluza y del mediodía español (desconocido, p. ej., en la prov. de Almería) [III, 584b9-15]

La explicitación sobre el desconocimiento del referente es otra de las noticias en que la ausencia de información resulta relevante.

\subsubsection{LEGÓN}

En Almería se aplica popularmente a la mujer que anda con muchos (también se le llama escardillo); otras veces con sentido más indulgente, pero en tono de reconvención, lo aplican los padres a sus hijos. [III, 625a29-33]

\subsubsection{MENDRUGO}

Finalmente otra posibilidad me la sugiere la ac. 'bulto de carne o de grasa en el cuerpo de una persona', que conozco como muy viva en Almería (...) [IV, 35a39-42]

\subsubsection{0. МоСHO}

\section{Contiene un nuevo fraseologismo de esta muestra:}

Remochar 'machacar, aplastar' oído muchas veces en Almería, en la frase remocharle la cabeza a uno 'reventarle, aplastarle' [...] (IV, 96b29-31)

\subsubsection{MORCILLA}

La composición de la morcilla varía mucho según las regiones: por conocimiento directo observaré que en Navarra le ponen mucho huevo, en Almería arroz [...] (IV, 140a14-17] 


\subsubsection{2. МИСНАСНО}

chacha vale 'niñera' en unas partes [...], 'hermana mayor' en otras muchas (como Almería). [IV, 177b51-53]

Semejante información figura bajo la entrada de TAITA y TATA, a propósito del uso de tata como nombre infantil de la hermana mayor en muchas partes de España, que envía a la nota 5:

De ahí seguramente chacha, como diminutivo palatalizado, de tipo vasco; aunque este nombre de la hermana mayor es usual hasta en Almería [...] $(\mathrm{V}, 381 \mathrm{~b} 2-5)$

\subsubsection{NUBE}

hoy nublo m. 'nube' se oye en Almería y en hablas orientales sobre todo [...] [IV, 241b1416]

\subsubsection{PANZA}

En relación con la variante pancha, que recoge el DRAE (s. v. pancho ${ }^{1}$, cha) como «[v]ientre, barriga, panza» [ac. 4, "coloquial"], se mencionan las formas derivadas panchufla y panchuflo:

el derivado panchufla 'moflete, carrillo abultado', que tengo anotado de Almería, junto con panchuflo adj. 'mofletudo' [...] (IV, 379b6-8)

\subsubsection{PARQUE}

A propósito del topónimo Berchul(es), que Coromines explica en cierto trabajo anterior (1959) a partir de un *PORTICIOLUS 'portezuelo', el etimólogo demuestra gran familiaridad con el territorio descrito:

Luego de ahí será verosímil que venga Berchul [1492; S. XVI; hoy Los Bérchules], pueblo que está en la grande y vieja carretera de Almería a las Alpujarras, al pie mismo del portezuelo por donde pasa del valle de Ugíjar (Río Grande) al del río Guadalfeo [...] (IV, 408b32-37)

\subsubsection{PARROQUIA}

De una variante parropia, localizada «en Gascuña, País Vasco y seguramente en algún dialecto castellano» [IV, 414a34-36], saldría «el and. purrupiala 'buena pieza, fulana, mujer poco recomendable' (< parropiala), oído en Almería» [IV, 414a40-42].

\subsubsection{QUIJADA}

Son sinónimos de esta forma el murciano quijar, que el DCECH remite a García Soriano (1932: 105), y quijal, «que hoy se oye en boca de rústicos hasta la prov. de Almería por lo menos» [IV, 725b37-41]. 


\subsubsection{PILLAR}

hoy pillar 'coger' es palabra de sabor muy vulgar, pero bien arraigada en muchas partes: p. ej. en Almería (pilló la manta y se fué a dormir) [IV, 547b25-28]

Como en otros casos, el ejemplo transcrito sugiere un testimonio de primera mano.

\subsubsection{REHILAR}

En Almería los gitanos emplean rilar por 'defecar' (probablemente de rehilar, como eufemismo, por ser ambas cosas efecto fisiológico del miedo [...]). [IV, 856b15-19]

\subsubsection{REZONGAR}

puedo atestiguar que en Almería es común emplear rezar figuradamente en el sentido de ‘hablar entre dientes, refunfuñar' [IV, 906a17-19]

El DRAE (s. v. rezar) registra dicho valor como coloquial: «6. intr. coloq. Gruñir, refunfuñar».

\subsubsection{RoBÍN}

también he oído rubín en Almería. [V42a58]

El DRAE remite de rubín a robín («Orín o herrumbre de los metales»).

\subsubsection{ROZAR}

Desde acepciones más etimológicas como 'cortar matas' o 'cortar maleza', se explica cierta acepción afín:

se ha podido llegar hasta 'cortar un hilo', ac. que he oído en Almería [V, 78b53-55]

\subsubsection{RUвIO}

Rubial «se llama el terreno que es de color rubio» (Aut.), según Acad. sería adj., pero en Almería se emplea como sust. (un rubial o tierra de rubial) y conserva allí el sentido etimológico de 'tierra de color rojizo intenso' [...] (V, 81a37-42)

De hecho, la edición que cito del DRAE registra el adjetivo rubial ${ }^{2}$ y el sustantivo rubial $^{1}$, pero este con otro sentido: «Campo o tierra donde se cría la rubia [cierta planta]».

\subsubsection{SABAÑÓN}

De entre las variantes de dicho tipo léxico, de origen incierto, se menciona el plural sabaions, localizado en el catalán de Castanesa (Huesca) y en el de Taüll (Valle de Boí), así como una forma castellana afín: «sabayones, que he oído en Almería y se emplea en Navarra» [V, 108b17-18]. 


\subsubsection{SALCHICHA}

chicha se emplea como nombre infantil de la carne en Almería y en muchas partes [V, 137a47-49]

\subsubsection{SANDÍA}

el uso de sandía y variantes no ha sido nunca general; en algunas partes de América se dice melón de agua, así lo he oído en Almería, y Aut. lo da como propio de Murcia. [V, $147 \mathrm{~b} 2-6]$

El DRAE (s. v. melón) remite melón de agua a sandía. El ALEA (mapa 334. Sandía) registra melón de agua en distintos puntos de la provincia almeriense, y asimismo Salvador (1953: 160) en Cúllar (Granada), donde «es la designación usual para la sandía, llamándose al melón, como contraste, melón de pan».

\subsubsection{SAPO}

Ofrece testimonios peninsulares de la variante con z-inicial zapo:

zapo es forma antigua, y hoy se oye en todo el Alto Aragón, desde Ansó hasta Venasque [sic], también en la parte baja de esta región (Caspe, Puebla de Híjar), en Murcia [...], y lo he oído en Almería. [V, 157a2-6]

\subsubsection{SEMILLA}

Nota 3: [...] en la prov. de Almería sólo semiente es popular [V, 201b12-13]

\subsubsection{SEÑA}

Nota 4: Enseñarse para 'aprender' [...] hoy es propio sobre todo de Andalucía (muy vivo en Almería, donde apenas se oye aprender $[\ldots](\mathrm{V}, 210 \mathrm{~b} 55-60)$

\subsubsection{TALVINA}

Hoy en la provincia de Almería se entiende por talvinas unas gachas secas, sin caldo, fritas en la sartén y por lo común con trozos de chorizo, tocino o pan. [V, 392a60-b4]

La referencia paralela del DECat (s. v. talvina) personaliza inequívocamente en su "inolvidable", aun sin nombrarla, la vivencia de la esposa siendo niña. Curiosamente, los años indicados entre paréntesis, 19301937, cabe relacionarlos con el tiempo en que habría conocido a la que, en 1936, se convirtió en su mujer (véase el apdo. 1):

\footnotetext{
A la meva inoblidable li havien donat, quan era nena, a les muntanyes d'Almeria, talvinas «gachas secas, sin caldo, fritas en la sartén y por lo común con trozos de chorizo, tocino o pan» (1930-37) [VIII, 247b3-7]
}

\subsubsection{TIZA}

La forma tizo, extraída regresivamente a partir de tizón, tal como señala el DCECH (s. v. tizón; V, 513a20-21), es recogida asimismo en el artículo TIZA: 
tiza significa 'tizón quemado casi enteramente' en el Alto Aragón [...], y tizo con el mismo sentido figura ya en Quevedo y hoy se emplea en Almería y en muchas partes. [V, $512 \mathrm{~b} 41-45]$

\subsubsection{TOBILLO}

Se trata en este artículo sobre el carácter primario o secundario de la «forma vulgar tubillo que hoy se oye no sólo en Méjico y Colombia, sino también en muchos puntos de España (p. ej. en Almería)» [V, 515b21-24].

\subsubsection{TOSTAR}

Aborda la forma alternativa torrar, propia de otros romances (occitano, catalán, gallego), pero también conocida en castellano: «torrar en judeoespañol de Oriente [...], en Almería y otras zonas andaluzas» [V, 568a43-45]. El DRAE remite de torrar a tostar.

\subsubsection{TotovíA}

Recoge una variante de esta voz de origen onomatopéyico: «En muchas partes se pronuncia tutuvía (p. ej. Almería)» [V, 569a19-20].

\subsubsection{VIENTO}

Como masculinización de ventana, se anota «ventano 'ventana pequeña' (muy vivo, p. ej., en Almería [...])» [V, 807a27-28]. Es forma recogida por el DRAE.

\subsubsection{ZÁBILA}

es la única pronunciación de que tengo noticia en la lengua moderna: oída muchas veces en Almería y otras partes de España [VI, 27a20-23]

El DCECH la atribuye asimismo a Cuba y Colombia. El DRAE remite zábila a áloe (o aloe) y localiza este nombre de planta en varios países de Hispanoamérica: Antillas, Colombia, Ecuador, Honduras, México, Nicaragua, Perú y Venezuela.

\subsubsection{ZАMPOÑA}

Nota 1: En castellano lo único que me consta es que cosa y nombre son muy populares en Andalucía; en Almería la zambomba se hace [...] con una orza o una boca de cántaro y una piel de conejo. [VI, 65a24-29]

\subsubsection{9. ¡ZAPE!}

Es voz de creación expresiva u onomatopéyica, y presenta variantes como la mencionada en este pasaje: «En Almería para alejar el gato dicen jsipe!» [VI, 80b18-19]. 


\title{
3.6.80. ZATICO
}

De un cruce de zatico con algún sinónimo deriva quizá zalanco, que he oído en la prov. de Almería para 'pedazo grande de pan'. [VI, 104a21-23]

\subsubsection{ZUMBAR}

De otra forma onomatopéyica, zurrir, deriva zurrido: «popular, p. ej., en Almería, donde se aplica al ruido de las gallinas que pican en el suelo» [VI, 123a1-3].

El DRAE registra zurrido ${ }^{1}$ : «Sonido bronco, desapacible y confuso». Alcalá Venceslada (1998: 665-666), en dos entradas distintas, lo que no serán sino acepciones del mismo tipo léxico zurrío: «Ostentación, presunción con bulla y ruido»; «Ruido bronco, como el del mar, de un río, etc.».

\subsubsection{Testimonio adicional}

Y añadiré por fin un testimonio del DECat (s. v. suro) para el que no encuentro correlato en el DCECH. A propósito de zuro, y tras una remisión a Alcalá Venceslada [1998: 665], ${ }^{15}$ señala Coromines en su diccionario catalán: «jo mateix vaig sentir-ho a les muntanyes d'Almeria: Aúro 'suro' a vells de Bédar, 1938» [IX, 147a22-24].

\section{A MANERA De CONCLUSión}

Bajo el epígrafe Ironía de la historia, Várvaro (2008: 275-278) escribe sobre la renuncia de Coromines a actualizar sistemáticamente sus propios vaciados de cara a la redacción y culminación de las tres grandes obras (el DECat, el DCECH, el Onomasticon Cataloniae) que ocupan el último tercio de su vida:

\begin{abstract}
A la hora de la verdad, lanzado a una ambiciosa carrera contra el tiempo para terminar el DECat y el OnCat [Onomasticon Cataloniae], el autor había decidido no tener en cuenta, incluso en el DCEH [DCECH] (para el cual contaba con la valiosa colaboración de José Antonio Pascual), la investigación de los últimos decenios. La ironía de la historia es que esta investigación más reciente en buena parte fue motivada precisamente por el DCEC [DCELC, 1954-1957]. Pero, paradójicamente, ello no les procuró ningún provecho a las obras posteriores de su propio autor. (Várvaro 2008: 275-276)
\end{abstract}

Su decisión de priorizar la organización de los materiales ya acopiados y de acometer la redacción definitiva de estas tres grandes obras lo lleva a prescindir de la consulta de publicaciones de aparición más reciente, como algunos de los atlas lingüísticos dirigidos por Manuel Alvar, que le habrían sido de gran utilidad a la hora de afinar la plasmación geográfica de ciertos datos.

\footnotetext{
${ }^{15}$ Donde se lee como definición de zuro: «Rodaja de corcho para tapa de cántaro».
} 
Concretamente el primero en publicarse, el ALEA (1961-1973), le hubiera procurado datos más precisos que los que toma de la primera edición (1933) o la segunda (1951) del Vocabulario andaluz de Alcalá Venceslada (véase mi nota 8): así, en casos como los de ranueco (3.3.3), amapol (3.5.2), dedo catite (3.5.6), jínjol y jinjolero (3.6.4), perfolla (3.6.29) o melón de agua (3.6.66).

Esa renuncia deliberada al vaciado de obras que aún hoy resultan de referencia, como el ALEA, contrasta con el aprovechamiento de una documentación "íntima" y antigua, que sin duda proviene de la esposa, y no de la investigación in situ de la tierra natal de esta, pues no hay constancia de que Coromines llegara a poner los pies en Bédar o en tierras almerienses. Aun así, recurre a la notación parentética de algún año de referencia en diversos pasajes del DECat, ni más ni menos que como cuando ofrece datos del dominio lingüístico catalán o, más ocasionalmente, de tierras contiguas como el Alto Aragón o las hablas castellano-aragonesas de la Valencia interior; ${ }^{16}$ datos que él mismo había recogido en alguna visita o prospección sobre el terreno.

En cualquier caso, el recurso a la metonimia de "la tierra natal por la persona nacida en ella" cobra una dimensión retrospectiva especial cuando se sitúa de manera críptica en algún año anterior a la mitad del siglo XX. Los testimonios dispersos en la muestra del apartado 3 cubren un espacio de tiempo que abarca de los años 20 a los 40. Reúno a continuación dichos pasajes fechados, por orden cronológico y con la remisión al punto correspondiente en la muestra:

«Capuzón de la Virgen pura, / que no me dé frío ni calentura», formuleta que recitaven els noiets a Bédar, c. 1920, abans de capbussar-se en una bassa. [3.6.17]

A la meva inoblidable li havien donat, quan era nena, a les muntanyes d'Almeria, talvinas «gachas secas, sin caldo, fritas en la sartén y por lo común con trozos de chorizo, tocino o pan» (1930-37) [3.6.70]

he sentit hínholes jo mateix a gent de les muntanyes d'Almeria (1936) [3.6.4]

cf. la forma castellana antiquada zaragüel, -eles (1490-1575), que és encara la més usada popularment cap a Almeria[,] etc.: «lleva unos pantalones tan paridos que parecen un Өaragwél» (1938) [3.2.20]

«jo mateix vaig sentir-ho a les muntanyes d'Almeria: Oúro 'suro' a vells de Bédar, 1938» [3.6.82].

Jo ho he oït al NNE. D'Almeria (on distingeixen garbillo, l'usat per al blat, de zaranda, el de l'arròs, 1944) [3.5.14]

[...] en la forma que em puntualitzava la dona d'immarcescible record, parlant de la fruiteta: «almecinas... no: latones, como decimos allí» (Bédar, Almería, 1948). [1, 3.5.16] «perro curto, caballo curto 'escuat' serres d' Almeria (1948)» [3.5.9]

La especial sensibilidad vertida en alguna de las alusiones elusivas parece explicable por el hecho de utilizar la propia lengua materna, algo impensable en

\footnotetext{
${ }^{16}$ Las llamadas "hablas churras". Para el tratamiento del léxico correspondiente en el DECat y en el DCECH, véase Gargallo (2007).
} 
el uso más neutro y distante, menos sentido, del castellano en el DCECH: «la dona d'immarcescible record» invierte el orden del sintagma con respecto al de la poesía evocadora de «la dona de record immarcescible» (véase el apartado 1); «la meva inoblidable» aparece en otro pasaje sin fechar: «de Bédar, NE. D’aquesta ciutat, la meva inoblidable coneixia bé cisca [...]» (3.5.22).

En el DCECH no aflora ese mismo sentimiento. Ahora bien, en compensación, y como corresponde a la implicación de lo almeriense en el ámbito hispánico que el diccionario cubre, son frecuentes los testimonios que manifiestan de uno u otro modo cercanía al lugar de origen de la esposa:

- Elementos de la cotidianidad vivida, como las talvinas o gachas de la tierra (3.6.70), la composición de las morcillas hechas con arroz (3.6.51) o la hechura de la zambomba (3.6.78).

- Mención de topónimos de Bédar o zonas próximas: El Marchal (3.5.1), Centinares (3.5.7), Los Matreros (3.5.18), los Vilorentos (3.5.24), Los Bérchules (3.6.55). Y un antropónimo, Curra, convertido en el apodo hereditario de cierta familia de Bédar (3.4.1).

- Muestras impagables de cultura popular: como la del lero, bicho que vive oculto en un agujero que él mismo se abre en el suelo y al que los niños persiguen cantándole lero, lero, sal del agujero (3.5.17); o la de la fórmula recitada por los niños de Bédar antes de darse un capuzón («Capuzón de la Virgen pura, / que no me dé frío ni calentura»: 3.6.24).

- Fraseologismos: parecer un cenizo (3.1.4); no hay ni un zotín, no dejó ni un zotín (3.1.9); tomar por burro de esquila (3.4.3); a cagilones ('en gran cantidad') [3.5.4]; remocharle la cabeza a uno (3.6.50).

- Ejemplos extraídos del habla viva: "parecer un caporal” (3.6.11); no tiene conocio, perdió el conocio (3.6.19); tiene los labios custridos, pan custrido (3.6.22); pilló la manta y se fué a dormir (3.6.58).

- Detalles sobre la fonética local: ¿pwé ntóh ké? (= ¿pues entonces qué?) [3.6.28]; cebrero por febrero, por equivalencia acústica (3.6.36).

El fino "oído" de Coromines se percibe en los 52 registros de dicha secuencia textual: «oído», con valor participial, que en 37 ocasiones forma parte del tiempo compuesto «he oído». Y se podrían haber contabilizado algunos más, pues la muestra resulta de una criba anterior. Por otra parte, esta misma muestra registra un par de veces «oída» (3.2.10, 3.6.76), en concordancia con un sustantivo en femenino; en otro par de pasajes, el pretérito en primera persona «oí»; y 9 registros de «se oye».

La constancia del testimonio oído da fe de que los datos provienen de fuente oral. Las alusiones elusivas a la persona de su mujer dejan entrever la particular sensibilidad del etimólogo, la humanidad de quien se expresa desde el sentir más etimológico del recuerdo. 


\section{BIBLIOGRAFÍA}

AlcalÁ Venceslada, A. (1998), Vocabulario andaluz, Edición facsímil de la impresa por la Real Academia Española en el año 1951. Anexo de más de setecientas autoridades literarias inéditas recogidas por el autor. Estudio preliminar y edición por Ahumada, I., Jaén, Universidad de Jaén/CajaSur.

Alvar, M., con la colaboración de Llorente, A. y SAlvador, G. (1961-1973), Atlas lingüístico y etnográfico de Andalucía, Universidad de Granada, CSIC, Granada [6 vols.] (ALEA).

BeCERRA HiRALDO, J. M. y VARGAs LABelLa, C. (1986), Aproximación al español hablado en Jaén, Granada, Universidad de Granada.

COROMinAS, J. (1954-1957), Diccionario crítico etimológico de la lengua castellana, Gredos, Francke, Madrid, Berna [4 vols.] (DCELC).

COROMINAS, J., con la colaboración de PASCUAL, J. A. (1980-1991), Diccionario crítico etimológico castellano e hispánico, Madrid, Gredos [6 vols.] (DCECH).

COROMINES, J. (1980-2001), Diccionari etimològic i complementari de la llengua catalana, Barcelona, Curial, la Caixa [10 vols.] (DECat).

COROMINES, J. (1989-1997), Onomasticon Cataloniae. Els noms de lloc i noms de persona de totes les terres de llengua catalana, Curial Edicions Catalanes, Caixa d'Estalvis i de Pensions «La Caixa», Barcelona, [8 vols.].

COROMINES, J. y PASCUAL, J. A. (2012), Diccionario crítico etimológico castellano e hispánico [Edición en CD-ROM realizada por el Seminario de Filología e Informática de la UAB; dirección: Gloria Clavería; coordinación: Joan Torruella], Madrid, Gredos [adjunta un Manual de ayuda al usuario, 46 pp.] (DCECH 2012).

GARCÍA SORIANO, J. (1932), Vocabulario del dialecto murciano, Madrid.

GARGAllo GIL, J. E. (2007), "Joan Coromines i el lèxic dels altres valencians", en Zeitschrift für Katalanistik, 20: 35-61.

Julià LunA, C. (2012), Variación léxica en los nombres de las partes del cuerpo. Los dedos de la mano en las variedades hispanorrománicas, Frankfurt am Main, Peter Lang.

PEREA, M. P. (2006), “Un biofic corominià, o la sublimació del gènere biogràfic”, en Els Marges, 79: 105-118.

PUJADAS I MARQuÈS, J. (2008), “Notas biográficas de Joan Coromines", en Joan Coromines, vida y obra, Badia i Margarit, A. M. y Solà, J. (eds.), Madrid, Gredos, 512-562.

ReAl ACADEMia EsPañola (200122), Diccionario de la lengua española, Madrid, Gredos. También accesible en línea: http://lema.rae.es/drae/ (DRAE).

SALVADOR, G. (1953), "Aragonesismos en andaluz oriental", en Archivo de Filología Aragonesa, V: 143-165.

VÁRVARO, A. (2008), "Joan Coromines y la lingüística románica", en Joan Coromines, vida y obra, Badia i Margarit, A. M. y Solà, J. (eds.), Madrid, Gredos, 254-281.

VENY, J. (1988), "Llei fonética, onomatopeia i polisèmia en els noms catalans del 'grill'", en Miscellanea di studi romanzi oferta a Giuliano Gasca Queirazza, Cornagliotti, A., Fontanella, L., Piccat, M., Rossebastiano, A. y Vitale-Brovarone, A., Alessandria, Edizioni dell'Orso, II, 1073-1095. 